\title{
Argument focus in Kar (Senufo)
}

\author{
Klaudia Dombrowsky-Hahn \\ University of Bayreuth
}

Focus theories distinguish different types of focus according to the pragmatic conditions or communicative point on the one side and different scopes of focus on the other side. The assertion in term focus constructions (Dik 1989), called by others argument focus constructions or identificational sentences (Lambrecht 1994), has the purpose of establishing a relation between an argument and an open proposition. Kar, a north-eastern Senufo language of Burkina Faso, which has the basic word order S-Aux-O-V-other, has at its disposal different strategies to mark argument focus, among them fronting of the focused item. In many West African languages the displacement of the focused argument involves other devices, such as the use of special verb forms. In Kar fronting of a focused argument requires the use of special pronouns in the out-of-focus part of the sentence, called background subject pronouns. They are used in other backgrounded contexts, too, for example in relative clauses, adverbial clauses and constituent questions. Their inconsistent use is attributed to a particular sociolinguistic situation in which the data has been collected. The use of the same focus strategies for completive and contrastive focus suggests that Kar does not distinguish pragmatic conditions on the level of sentence grammar.

\section{Introduction}

\subsection{Theoretical considerations}

Dik (1989) defines focus as a formally marked pragmatic function attaching to the most important or salient information in the given communicative setting with respect to the modifications which the speaker wishes to effect in the pragmatic information of the addressee and with respect to the further development of the discourse. Lambrecht (1994) specifies that focus is that semantic element that makes a proposition into an assertion, and consequently, into a potential piece of information. It follows that each proposition has to have a focus to be informative. Different focalizing devices like prosodic prominence, 
special constituent order, focus markers and special constructions serve to distinguish several communication points on the one side and various scopes of focus on the other side.

The following typology of focus in Dik et al. (1981 - reproduced among others in Drubig \& Schaffar 2001) and its revised version (Dik 1989, I) from which the example sentences are adopted have been established on the basis of languages like Aghem, a Grassfield Bantu language, where a rather wide range of structural distinctions in the coding of focus corresponds to differences of pragmatic conditions (Watters, cited in Dik et al. 1981). The main difference is that between completive and contrastive focus, whereby the last one is subdivided into some other categories as shown in figure 1. Completive focus corresponds here to an assertion $\mathrm{X}$ that fills the gap in an open proposition as it appears in wh-questions, reflecting the addressee's ignorance, for example in the following sequence adopted from Dik (1989, I: 328):
A: Where is John going?
B: (a) John is going to the MARKET.
(b) To the MARKET.

Contrastive focus is a reply to the addressee's contrary belief of information. For Dik et al. (1981: 58) the term 'contrast' refers to a "[...] case in which one piece of information, say $x$, is explicitly or implicitly opposed to some other piece of information, say $\mathrm{y}$, which stands in some specific relation of opposition to $\mathrm{x}$ in the given setting".

The terms of completive and contrastive focus have different synonyms in the literature: completive focus is sometimes also called presentational focus, information focus or focus of assertion, while contrastive focus is known as identificational focus, operator focus or narrow focus ${ }^{1}$.

1 See especially Kiss (1998), whose terminology is based on semantic and syntactic grounds. 
Figure 1 Typology of focus according to Dik et al. (1981)

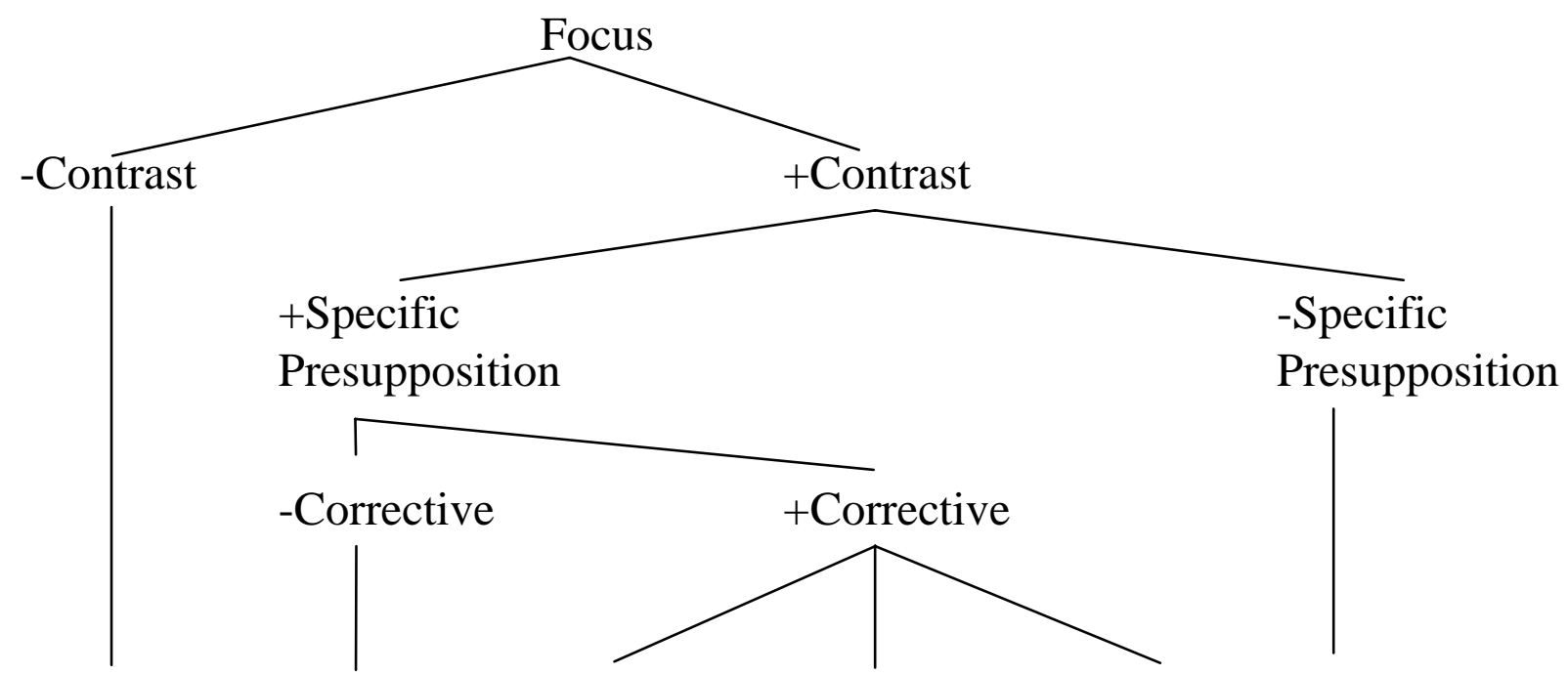

Completive Selective Expanding Restricting Replacing Parallel

\begin{tabular}{|c|c|c|c|c|}
\hline $\begin{array}{r}\text { A: Would } \\
\text { you like } \\
\text { coffee or } \\
\text { tea? }\end{array}$ & $\begin{array}{c}\text { A: John } \\
\text { bought } \\
\text { apples. }\end{array}$ & $\begin{array}{r}\text { A: John } \\
\text { bought } \\
\text { apples and } \\
\text { bananas. }\end{array}$ & $\begin{array}{c}\text { A: John } \\
\text { bought } \\
\text { apples. }\end{array}$ & $\begin{array}{r}\text { JOHN bought } \\
\text { APPLES, BOB } \\
\text { bought } \\
\text { BANANAS. }\end{array}$ \\
\hline
\end{tabular}
S: COFFEE, S: Yes, S: No, he S: No, he please. but he also only bought bought bought BANANAS. BANANAS. APPLES.

While some, but not all languages, make distinctions in the coding of focus types according to the pragmatic conditions mentioned above, most languages distinguish the coding of focus according to its scope. Dik (1989, I: 330) makes out constructions where one of the following constituents is in focus:

1) a predicate operator, like in: John HASn't painted the house, he Is painting it right now,

2) the predicate itself or a part of it: I didn't PAINT the house, I REpainted it,

3) a term, (subject or another term) as demonstrated in the examples above where the different types of focus have been discussed.

Lambrecht (1994), who among others is interested in pragmatic functions topic and focus as constituent parts of information structure, does not distinguish Dik's categories 1) and 2), subsuming them under the type he calls topic- 
comment sentences. The purpose of the assertion of topic-comment sentences is to "pragmatically predicate some property of an already established discourse referent" (Lambrecht 1994: 126). Topic-comment sentences where the focus is on the predicate constitute the unmarked type of sentences. Dik's category 3) corresponds to Lambrecht's identificational sentence where the assertion has the purpose of establishing a relation between an argument and an open proposition. Here, the focus is on the argument. Additionally to Dik's categories, Lambrecht (1994: 233ff) recognizes another kind of sentences, the event-reporting sentences. The assertion in these sentences has the purpose of expressing "a proposition which is linked neither to an already established topic nor to a presupposed open proposition" (Lambrecht 1994: 126). The focus lies here on the entire sentence, which means on the argument(s) and the predicate. These structures correspond to thetic sentences, lacking a topic and thus lacking the bipartite structure of topic and comment characteristic of categorical sentences. They are found in replies to the question 'what happened?' or 'what's the matter', for ex. in the German: 'Mein HALS tut weh', 'My THROAT hurts' as opposed to the categorical sentence 'Der HALs tut mir weh', 'My THROAT hurts', having an argument focus interpretation (Lambrecht 1994: 256).

\subsection{The aims of the paper}

In this paper, some aspects of focus in Kar, a Northeastern Senufo language of Burkina Faso, will be discussed. After the presentation of some typological characteristics of Kar, I shall describe the main focusing devices of argument focus. The main focus strategies in Kar will be exemplified on clauses with different arguments in focus (syntactic subject, direct object and oblique object), whereby special attention will be paid to the marking of the out-of-focus part of the sentences. Subsequently I shall discuss the question whether the language disposes of special formal means to differentiate the pragmatic conditions shown in Figure 1 above, in which case it would resemble languages like Aghem, or whether the means to code different types of focus are identical, which would make Kar more similar to Wambon, a Papuan language of Irian Jaya (Vries 1985).

\subsection{The Kar language}

Kar has, like other Senufo languages, the word order S - Aux - O - V - Other, where 'other' represents oblique objects or satellites, usually followed by a postposition. Nouns are distributed in 8 classes mostly according to their semantic properties. Six of them form singular - plural genders, the other two 
assemble non-countable entities. A vast system of pronouns and determiners is equally organised in those noun classes ${ }^{2}$.

The Kar verbs display primarily an aspect distinction: apart from a lexical base, each verb appears in perfective and imperfective forms, distinguished on the tonal level. However, the tonal distinction between the verb bases is neutralized when the verb is preceded by an object. In such cases, the tone of the object determines the tonal shape of the following verb, while the tone of the subject pronoun and eventually any auxiliary morphemes indicate tense, modality and aspect distinctions.

Following is an example of a sentence with an unmarked predicate focus, bearing the canonical word order Subject - Auxiliaries - Object - Verb - Other, as shown in example (1).

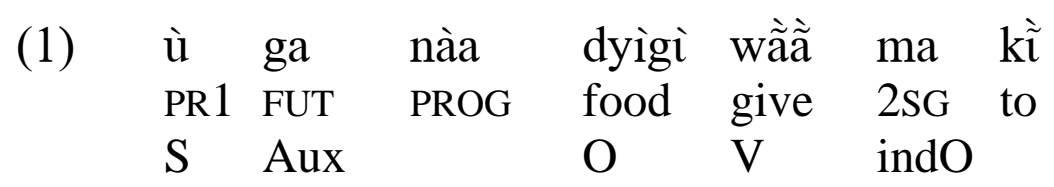

'He will provide you with food.' (lit. He will be giving food to you. (Musa 0885)

\subsection{The data}

The discussion of focus in Kar is based on data gathered in the town of Banfora in Burkina Faso in the context of the linguistic project A1 of the SFB/FK 560 at the University of Bayreuth. It consists of free interviews between different pairs of Kar speakers, resulting in conversational dialogues. According to Vries (1985: 171), conversational dialogues belong to this type of discourse where "[...] the development of saliency is generally more complex [...]" than in narrative discourse for example, in which topic continuity, which means the establishment and the maintenance of a topic is more important. Vries specifies that in conversations "[...] the speaker thinks the hearer needs more guidance as to what information he should pick up as salient" (1985: 171). Actually, the Kar data originating from conversations displays a great number of different focus constructions that will be exemplified in the following sections.

\section{Focus strategies in Kar}

Under the title of emphasis ('emphase', 'mise en relief') Creissels (1978) lists a number of focus devices appearing in more than twenty West African languages from different language families. He concentrates on sentences bearing

2 Cf. Dombrowsky-Hahn (to appear). 
argument focus and identifies an important range of focus devices which include a special morphology and word order change. According to the language under consideration, a special morpheme is 1) connected to the argument in focus (it follows or precedes it), and very often it is identical with the identificational morpheme ('prédicat d'identification') or 2) it is connected to the verb (here Creissels subsumes also the use of only tonally different verb forms in a marked vis-à-vis the unmarked sentence) or 3) it appears in the final position of the sentence. Word order change is applied differently according to the language: some languages do not displace the focused argument, making use exclusively of focusing in situ. Where the focused item is displaced in the initial position of the sentence, a pronoun may or may not recall the referent in its usual position. The author mentions that coexistence of different devices in one language is not rare; sometimes their use is conditioned by the syntactical nature of the focused constituent $^{3}$.

We shall see that the last of Creissels' statements is valid for Kar sentences with a focused argument. Among the strategies mentioned by the author we find constructions with focusing in situ using special focus morphemes, simple fronting of the focused item, fronting accompanied by a special focus morpheme following it and fronting accompanied by an identificational morpheme called a cleft construction even though it is very different from clefts in English or French. In addition, in all the constructions where displacement of the focused constituent is one of the focus devices it is combined to another one, not occurring in the sample of languages studied by Creissels: a special subject pronoun occurring in the out-of-focus part of the sentence.

\subsection{Focusing in situ}

Constructions where the focused term, followed by a special morpheme, remains in its usual position are not as frequent as constructions with a displaced constituent. Most frequently, the accompanying morphemes are those expressing contrast implicitly, such as ya 'only' and geE 'even', both invariable morphemes. More rarely a general focusing morpheme is found, bearing the form C-oò, corresponding to the paradigm of emphatic pronouns shown in table (1), which appear in agreement to the noun class of the referent. As will be demonstrated later, this kind of morpheme is frequently used with displacement

3 Creissels' interpretation is a structural study in reply to a typological account of emphasis phenomena by the generative linguist Maurice Coyaud. Creissels does not consider pragmatic conditions that may require different focus devices in a language. Given the scarcity of the material he had at his disposal for the study this wouldn't even have been possible. 
of the focused argument. Following a focused noun, the morpheme shows a variable tonal behaviour according to the tone of the noun. Alternatively the bare form of the morpheme, lacking the class marking consonant, sometimes with a glide, oo ou woò is used independently of the noun class to which the referent belongs.

Table 1: Noun class system of Kar with simple and emphatic pronouns

\begin{tabular}{|r|l|r|l|}
\hline \multicolumn{2}{|c|}{ singular classes } & \multicolumn{2}{c|}{ plural classes } \\
\hline emphatic & simple & simple & emphatic \\
\hline woò & $1 . \mathrm{u}$ & $2 . \mathrm{pl}$ & poò \\
\hline koò & $3 . \mathrm{kl}$ & $4 . \mathrm{tl}$ & toò \\
\hline loò & $5 . \mathrm{lt}$ & $6 . \mathrm{kl}$ & koò \\
\hline \multicolumn{3}{|c|}{ classes of uncountables } \\
\hline \multicolumn{3}{|r|}{ emphatic } & simple \\
\hline \multicolumn{3}{|r|}{ toò } & $7 . \mathrm{tr}$ \\
\hline \multicolumn{3}{|r|}{ poò } & 8. pr \\
\hline
\end{tabular}

The emphatic personal pronouns have, at least in the singular, similar forms (table 2):

Table 2: First and second person pronouns

\begin{tabular}{|l|l|l|}
\hline Person & simple & emphatic pronoun \\
\hline $1 \mathrm{sg}$ & $\mathrm{n}(\mathrm{ta})$ & ndoò \\
\hline $2 \mathrm{sg}$ & $\mathrm{ma}$ & mboò \\
\hline $1 \mathrm{pl}$ & wó & wéè \\
\hline $2 \mathrm{pl}$ & yé & yéè \\
\hline
\end{tabular}

The following utterance (2), a contrastive parallel construction containing two clauses, each with a direct object in focus ${ }^{4}$, exemplifies both kinds of focus

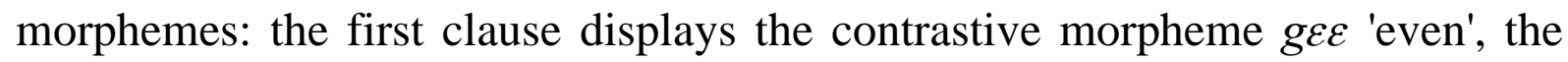
second one the general focus morpheme loo of class 5, in agreement with the reference noun wãl 'matter'. The verbs have opposite meaning; the first one being the negation of the second, the direct objects refer to entities which are elements of a set in the sense defined by Myhill \& Xing (1996).

(2) [Context: The sentence is uttered by a speaker reporting an accident which occurred when he was crossing a large river on a slippery log,

4 The two propositions are in fact interrupted by a relative, which is an explanative digression. This is why the different subject morpheme is used in the second proposition. 
carrying a big sack of corn. He had fallen into the deep water together with the food.]

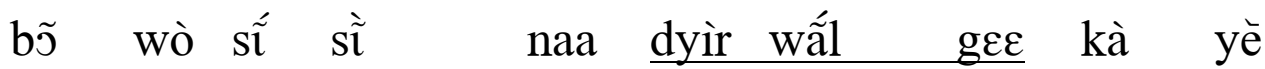
well 1PL NEG however PROG food matter5 even think NEG wo $\mathrm{n} \quad \mathrm{kl}$ ndoò yèrê $\quad$ wã̀lìgi wấl loo kà. 1PL DS DEF3 1SG.EMPH own(<Dy) coming.out matter5 EM5 think 'We didn't even consider the problem of the food, it was the problem of my own coming out we were thinking about.' (Seku 236-238)

\subsection{Focusing by fronting}

Fronting as a focus strategy involves some other devices, especially the use of particular subject pronouns in the out-of-focus part of the sentence and the use of a prefix in certain aspectual forms of the verb. As they are the same for the three fronting strategies described below, they will be given in detail only once, within the section 2.2.1.

\subsubsection{Simple fronting}

The most common strategy to focus a term is its fronting. If the focused item is a noun, it is just put in the initial position of the clause. The following two clauses are pragmatically distinct, (3a) is unmarked, and (3b) bears a focus on the fronted direct object wápwj.

(3) a. wo naa wápwò dyi yà?àmbaa.

1PL PROG cowrie1 eat moreover

'Furthermore we used to spend cowries.'

b. [Context: The speaker has already spoken about some differences between former times and the current period. Now he approaches the subject 'means of payment'. Money, the term that cowrie is contrasted with, is mentioned later.]

wápwò noo nàà ndyî yà?àmbaa.

cowrie1 1PLBACK PROG IP-eat moreover

'Furthermore, it is cowries we used to spend (lit. to eat).' (Ournan 0228) 
Beyond the position of the focused item, preverbal in the unmarked, sentence initial in the marked sentence, the comparison of the two utterances above shows two other differences. First, the simple subject pronoun in the unmarked sentence (3a) wo' 'we', is replaced by the background subject pronoun roo in the out-of-focus part of (3b), a clause where the direct object is displaced. The pronoun roo belongs to a paradigm of pronouns shown in table (3). The corresponding paradigm of third person pronouns is given in table (4). It is interesting to consider their form: the first and second person and the class 1 background pronouns maintain and lengthen the vowel of their simple counterparts, the initial consonant $t$ - (often realised $r$-) being here characteristic of the feature 'backgrounding'. The third person background pronouns except the one of class 1 on the other hand show the consonants characteristic of the noun classes and the vowel -ii. The contexts of their use will be discussed below in section 3 .

Table 3: First and second person simple pronouns and background subject pronouns

\begin{tabular}{|l|l|l|}
\hline Person & simple & background subject pronoun \\
\hline $1 \mathrm{sg}$ & $\mathrm{n}(\mathrm{ta})$ & $\mathbf{t} \tilde{\mathbf{i}} \sim \mathbf{r} \tilde{\mathbf{i}}$ \\
\hline $2 \mathrm{sg}$ & ma & taa $\sim$ raa \\
\hline $1 \mathrm{pl}$ & wó & too $\sim$ roo \\
\hline $2 \mathrm{pl}$ & yé & tee $\sim$ ree \\
\hline
\end{tabular}


Table 4: Third person (noun class) simple pronouns and background subject pronouns

\begin{tabular}{|r|l|r|r|}
\hline \multicolumn{2}{|c|}{ singular classes } & \multicolumn{2}{c|}{ plural classes } \\
\hline background & simple & simple & background \\
\hline tuu $\sim$ ruu & $1 . \mathrm{u}$ & $2 . \mathrm{pl}$ & bii $\sim$ pii \\
\hline kii & $3 . \mathrm{kl}$ & $4 . \mathrm{tl}$ & tii $\sim$ rii \\
\hline lii & $5 . \mathrm{lt}$ & $6 . \mathrm{kl}$ & kii \\
\hline \multicolumn{3}{|c|}{ classes of uncountables } \\
\hline \multicolumn{3}{|c|}{ background } & simple \\
\hline \multicolumn{3}{|c|}{ tii $\sim$ rii } & $7 . \mathrm{tl}$ \\
\hline bii & $8 . \mathrm{pr}$ \\
\hline
\end{tabular}

The second difference between ex. (3a) and (3b) concerns the verb forms used. In the unmarked sentence the verb $d y \hat{i}$ is directly preceded by the object; in the sentence with a fronted object the verb $n d y \hat{i}$ is not immediately preceded by the object and shows therefore a nasal prefix assimilating to the initial consonant of the verb. The nasal prefix on the verb appears in the imperfective aspect (including the progressive) when there is no direct object immediately preceding the verb. The most common context of the occurrence of this feature (which is well known in many Senufo languages) is their use as intransitive verbs, the reason why the prefix is called 'intransitive prefix'.

It is worth mentioning that if a part of a noun phrase has to be focused such as for example a numeral quantifying a noun, it is the entire noun phrase that is fronted. This is demonstrated in ex. (4a)

(4) a. [Context: Asked 'How many years have you spent in Ivory Coast?', the speaker answers:]
dyè
bwò
tóó
pyè dugu le.
years6(B) five
1PLBACK(B) do.PF forest in(B)
'We have spent five years in Côte d'Ivoire.' (Mlata 0119)

Correspondingly, the simplest answer to the interviewer's question, leaving out the out-of-focus part, would not be the quantifier alone but the entire noun phrase:
b. dyè
bwò.
years6(B) five
'Five.' 
In the above mentioned examples (3b, $4 a$ ) the focused argument is the direct object. Of course, other arguments can be focused, too. Example (5a) illustrates a focused subject. Its neutral counterpart would be example (5b). As its usual position is already sentence initial, a focused subject is not displaced but it is however recalled in the out-of-focus part of the sentence. So the differences between (5a) and (5b) are the following: the clause (5a) with a focused subject bears an emphatic first person pronoun wée, instead of a simple wó, and it is resumed by the background subject pronoun $r o o^{5}$.

(5) a. [Context:The speaker was asked about all the people working in his workplace. Having listed all of them, the speaker resumes ...]

$\begin{array}{llll}\text { wéè } & \text { róó } & \text { tũ̀n tũ̀ } & \text { ýwò. } \\ \text { 1PLEM } & \text { 1PLBACK:IMPF } & \text { work5(B)work(B) } & \text { here } \\ \text { 'It's us who are working here.' (Musa } & \text { 0269) } & \end{array}$
b. wó tũ̀n tũ̀ ýwò.
1PL:IMPF work5(B) work(B) here
'We are working here.'

Beyond direct objects and subjects, indirect objects and satellites can be focused by means of fronting. In the neutral form of a sentence, they follow the verb and, most of the time, are marked by a postposition. This is demonstrated in clause (6a):

$$
\text { 'We knew each other in that place.' }
$$

When focused, they are fronted without the postposition as ex. (6b) illustrates. In the mentioned example there is no case ambiguity, as the direct object (wí) is present in the presupposed part of the clause.

$$
\begin{array}{llllll}
\text { b. téc } & \text { koò } & \text { fla } & \text { too } & \text { wî̀ } & \text { cã? } \\
\text { isn't.it } & \text { EM3 } & \text { place } & \text { 1PLBACK } & \text { 1PLREF } & \text { know.PF } \\
\text { 'Isn't it in that place that we knew each other?' } & \text { (Mlata 0509) }
\end{array}
$$

5 The high tone on the pronoun roo marks imperfective aspect. 
As in the examples illustrating a subject and a direct object focused by fronting, here too the subject of the out-of-focus part is coded by a background subject pronoun.

Cases of focused indirect objects or satellites are rather rare. Concerning the latter ones one can hypothesise that this may be due to the fact that, according to Givón, optional elements attract the scope of assertion even in the usual word order, so focusing seems to be less necessary than in the case of a direct object for example.

\subsubsection{Fronting + focus morpheme}

The fronted item may be followed by any of the focus morphemes already mentioned: the morphemes implying contrast as for example ya 'only' and the morphemes corresponding to the emphatic pronouns. Ex. (7) contains a focused direct object, (8) a focused subject.

(7) [Context: The speaker calculates the years spent on migration according to his age.]

kl fằbáá wòò rĩ gá pì̀ ýwààlâ

PR3 big.part(<Dy)1 EM1 1SG:BACK go do.PF there

lúgù laam wô

forest inside in

'It's the biggest part (of my life) I have spent in Ivory Coast.' (Seku 198)

(8) [Context: When asked to tell a story, the speaker, an old man, answers that he has forgotten a lot. Then he explains that being a youngster he used to pass whole nights telling stories, but getting older ....]

láá lòò lii yí ýkãã̃ $\quad$ ma nà

INDEF5 EM5 BACK5 get.out IP-get.off:IMPF 2SG on

'(When you get older), things start to slip your mind (in the sense of 'there is even a lot that slips your mind').' (Ournan 0375).

\subsubsection{Fronting + identification morpheme}

The third kind of coding focus to be discussed here is a cleft construction, making use of an identification morpheme. The same identification morpheme functions as predicate in independent clauses. Its forms, figuring in the outside columns of table (5), agree with the noun class to which the focused item belongs. 
Table 5: Identification morphemes

\begin{tabular}{|c|c|c|c|}
\hline \multicolumn{2}{|c|}{ singular classes } & \multicolumn{2}{|c|}{ plural classes } \\
\hline ident. morph. & simple pronoun & simple pronoun & ident. morph. \\
\hline wũ̃ $\sim$ kĩ & 1. $\mathrm{u}$ & 2. $\mathrm{pr}$ & mi \\
\hline kì̃ $\sim$ jì & 3. $\mathrm{kl}$ & 4. $\mathrm{tl}$ & nì \\
\hline nì & 5.11 & 6. kl & kĩ \\
\hline \multicolumn{4}{|c|}{ classes of uncountables } \\
\hline & ident. morph. & \multicolumn{2}{|l|}{ simple pronoun } \\
\hline & nì & \multicolumn{2}{|l|}{ 7. $\mathrm{tl}$} \\
\hline & mì & \multicolumn{2}{|c|}{ 8. $\mathrm{pr}$} \\
\hline
\end{tabular}

Used in independent clauses, these morphemes have the function of identification or classification. In the data they appear often as commentaries or explanations of the discourse, interrupting it more than adding something to the thread of the discourse. They can thus be designated as thetic utterances (cf. Sasse 1987). This is the case in ex. (9), an extract of a conversation.

(9) [Context: The speaker was told the story of people who had to abandon their villages because the government established sugar cane fields on their surface. To save their goods, especially cowries, the villagers hid them in holes in the ground. However, strangers dug them out. The conversation partner goes on with the story after the following interruption.]

éeè kapã̀-pee nì

EXCL speach-bad5 IDENT5

'It is bad speech.' (Ournan 0337)

The same morphemes are used as focus morphemes in sentences with a fronted argument (10) and (11). The out-of-focus parts are characterized by the features required when an argument is fronted. 
(10) [Context: Asked about the difference of the Kar dialects spoken by the speaker and her husband and about what conditions the language one speaks she explains that one's natal village is decisive.]

lér klò yùr nì raa gà nàa

EM5(B) village5 language7 IDENT7 2SG.BACK FUT PROGR mpã̃ã.

PI:speak:IMPF

'It is the language of this village (the one you are born in) you will speak.' (Mlata 0200)

Example (11) illustrates the possibility of multiple marking of a focused item. Here, the negative question with a focused subject is marked by the identification morpheme $w \grave{\tilde{u}}$ and, in addition, by the morpheme ya 'only', implying a restriction.

(11) [Context: The addressee has spoken about his work. The place being rather big, it seems not to be possible that the addressee is the only person working there.]

mboò nìn ya sĩ wũ̀ táá tî̀n tĩ̀ 2SGEM one1 only NEG IDENT1 2SGBACK:IMPF work5 work ýwò yè re?

here NEG FOC

'But of course, you are not the only one who is working here, are you?' (Musa 0256)

The structure of the affirmative clause (12) is very similar to the negative question (11) with the only exception that in (12) the focused item is a satellite. As in all other utterances with a fronted satellite, the postposition common in unmarked sentences (here it would be kajigı nin ya nä) is dropped: 
(12) [Context: The speaker reports that during his stay in Ivory Coast he has lived near a river.]

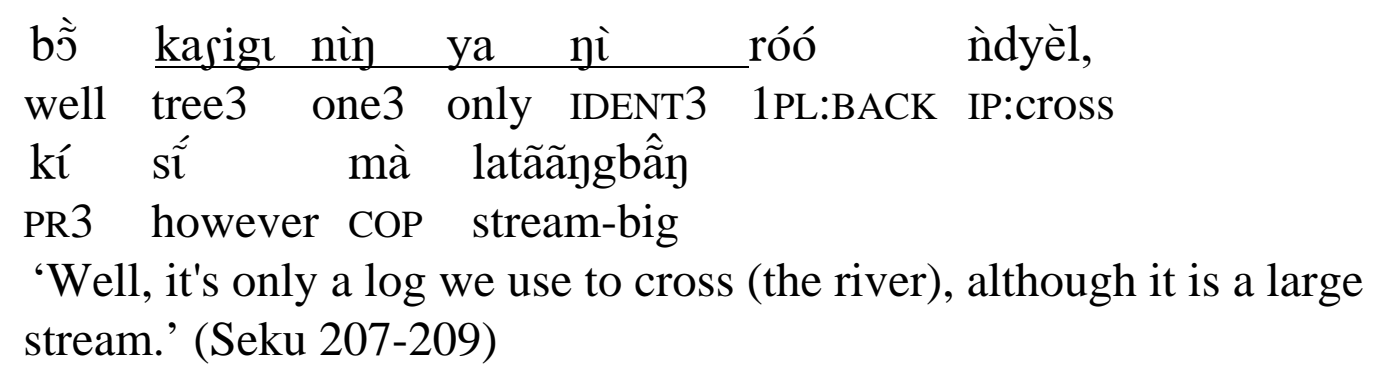

\section{Problem of coding the out-of-focus portion of the clause}

All three strategies involving fronting display the following characteristics: The fronted focused item is not resumed in the out-of-focus part of the sentence, except for a focused subject. Furthermore, in all constructions mentioned so far, we find only pronouns filling the subject function in the presupposed part of the sentence. This is not surprising, as the presupposed information concerns given participants or old information, characteristically subject to pronominalization (Chafe 1976). According to Lambrecht (1994), pronouns embody the participants that are considered to be active in the auditor's consciousness, most typically, active topics. In the examples presented up to now, the subject pronoun in the presupposed part of the sentence is what is called here background subject pronoun.

The background subject pronoun, called "pronom thématisé" or "substitutif thématisé" by Wichser in her description of Kar (1994: 280), is defined by the author as a subject pronoun representing the least informative term in a sentence. According to the author, special forms of this pronoun exist only for the first and second person pronouns and for class 1 . In the other classes the simple pronoun with high tone takes over the function of a 'pronom thématisé'. In our data however, the oldest of our informants uses forms for the other noun classes, too, as can be seen in table 4 and in ex. (8). On the other hand, we find a lot of examples where the simple pronoun (not always with high tone) is used in the subject function within the presupposed part, even if it is the first or second person pronoun. This is illustrated in utterance (13), which is only one of numerous cases where the presupposed part of the sentence starts with a simple (or another, for instance an emphatic) subject pronoun (here $\grave{n}$ ). 
(13) [Context: A merchant talking about the languages she speaks: If I hadn't travelled...]

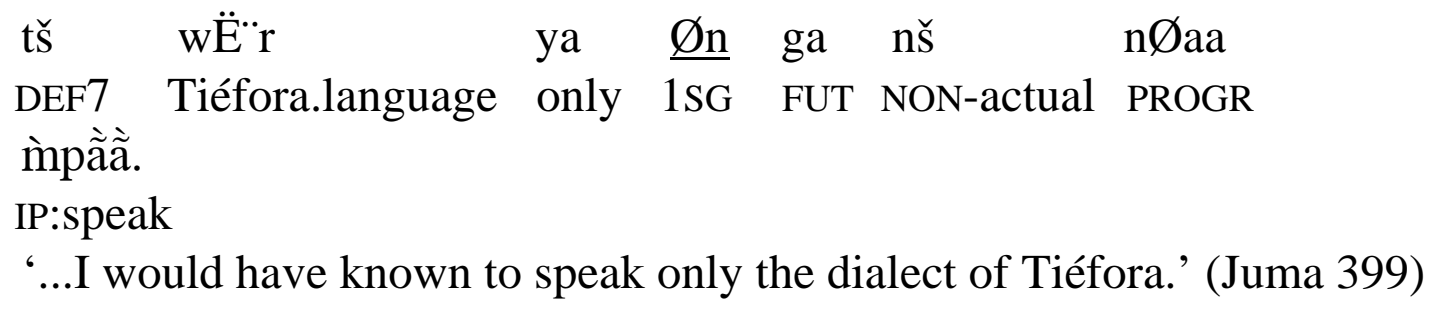

Background subject pronouns appear in several other contexts beyond the outof-focus parts of sentences with a fronted focused item. In all of the contexts the referent of the background subject pronoun is considered to be active in the auditor's consciousness and belongs to backgrounded information.

1) It appears in restrictive relative clauses modifying definite head nouns. Definite head nouns and the events coded in the relative clauses modifying them are identifiable, known or familiar to the addressee. Ex. (14) is a relative clause with the emphatic first person plural pronoun wée in subject function determined by the relative pronoun of class 2, mpĩ̀n and resumed by the first person plural background subject pronoun too:

(14) [Context: The speaker was asked about the persons who work with him at his work place.]

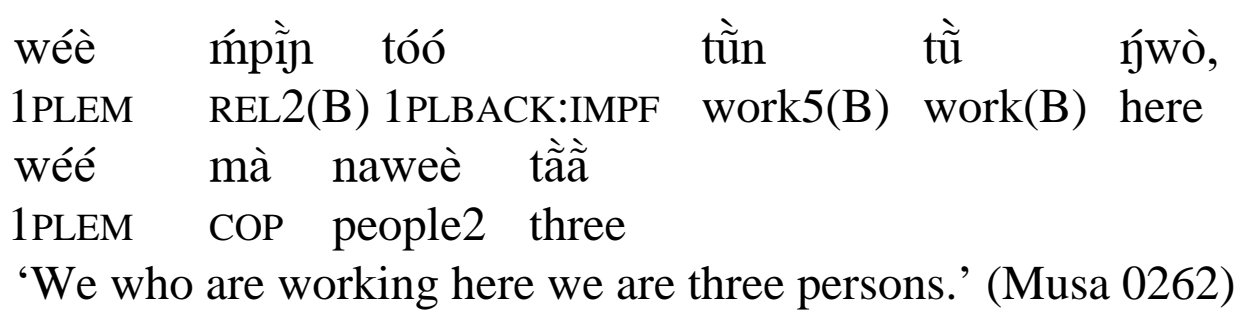

2) Another context of use of background subject pronouns is in adverbial clauses of time indicating the simultaneity of the events expressed in the subordinated clause and in the main clause. Usually the information conveyed in such an adverbial clause is backgrounded and has been mentioned before. In ex. (15) the speaker has just mentioned that he has spent 20 years in Ivory Coast, so the adverbial clause conveys some known, presupposed information, creating the background of the following main clause. 


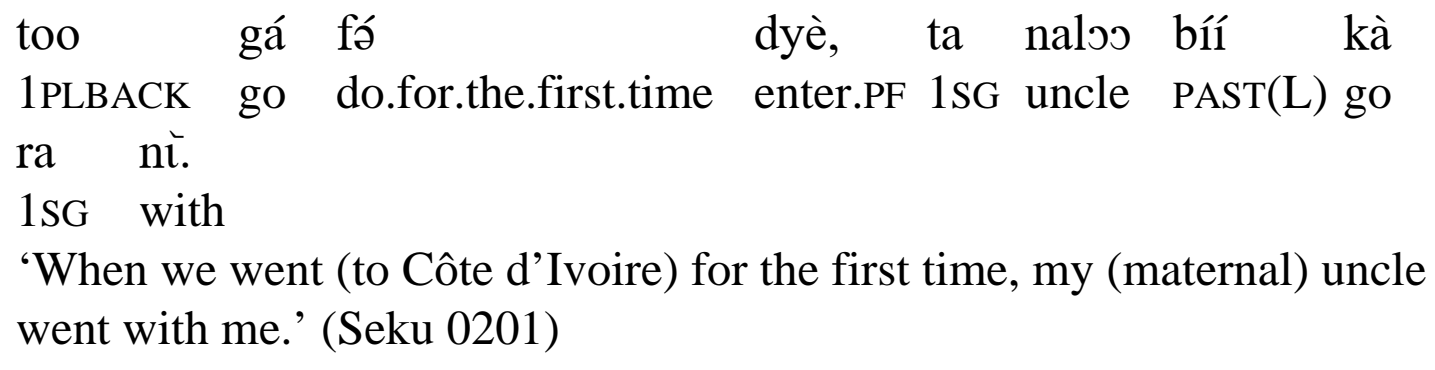

'When we went (to Côte d'Ivoire) for the first time, my (maternal) uncle went with me.’ (Seku 0201)

It is not surprising to name the relative and the adverbial clauses side by side using the same kind of pronoun. Usually time adverbial clauses can be paraphrased as relative clauses, with which they often share properties (Thompson \& Longacre 1985).

3) Other contexts displaying the background subject pronouns are constituent questions where the constituent consisting of or containing a question word is clefted. This construction, called by Dik Q-Focus (exemplified in ex. 16 and 18) because of its resemblance to focus cleft constructions, alternates in Kar with constituent Q-Pattern questions where the question word constituent is placed in situ (exemplified in 17) (Dik 1997: 278). Of course, it is only the Q-Focus construction that bears a background subject pronoun within the presupposed part.

(16) [Context: If you meet some Karaboro from another village, for example from Boussara, Séréfédougou or Ténguéréla, do you understand each other?]

$\begin{array}{llllll}\text { làà } & \text { yòr } & \text { ríi } & \text { nì } & \text { réé } & \text { mònã̀à? } \\ \text { or } & \text { language7 } & \text { INTER7 } & \text { IDENT7 } & \text { 2PLBACK:IMPF } & \text { IP-speak } \\ \text { 'Or, otherwise what language do you speak?' (Oti 0501) }\end{array}$

(17) [Context: Following a conversation about the parents' languages:]

àpı rícàr, póó yòr riipã̀à?

and DEF2 children PR2EM language7 INTER7 speak

'And the children, what language do they speak?' (Mlata 0222)

These are the main contexts of use of the background subject pronoun. Their inconsistent use has been observed in the presupposed part of clauses with fronted or clefted focus items and in their interrogative counterparts, the constituent questions with a clefted question word. As it is rather uncommon for a language to have two forms for exactly the same function, this brings about the 
question what conditions the use of one or the other kind of pronoun in such contexts.

It was not possible for me to see a functional distinction in the use of the one or the other sort of pronoun in clauses bearing argument focus: its use neither seems to depend on the aspect of the verb nor on the variety of the focus construction - simple fronting, fronting with a focus morpheme or cleft construction - nor on some nuance of the pragmatic conditions. What is more, sometimes, even the same speaker alternates between the use of the simple and the background pronoun when uttering almost the same question with different conversation partners as can be seen in examples (18) where it is a single person he addresses and (19) where two persons are the addressees:

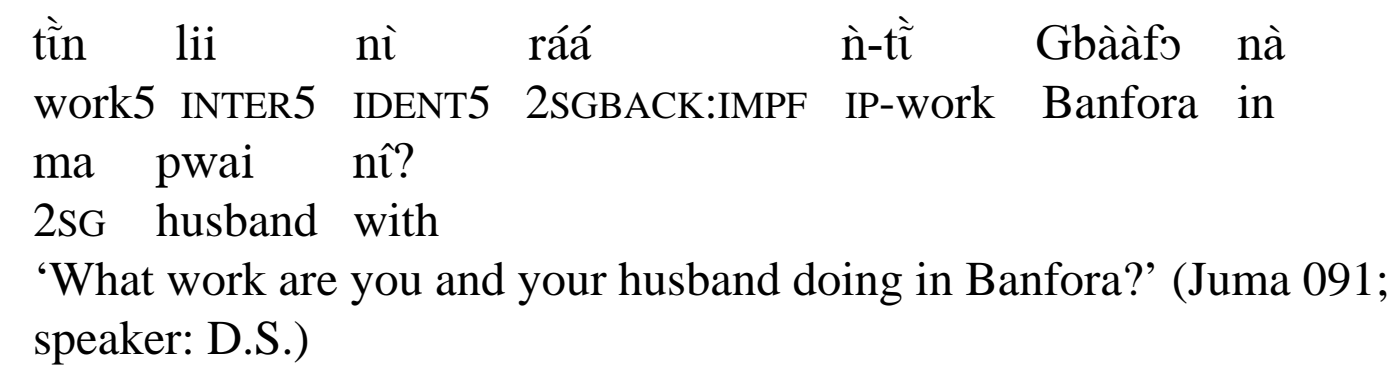

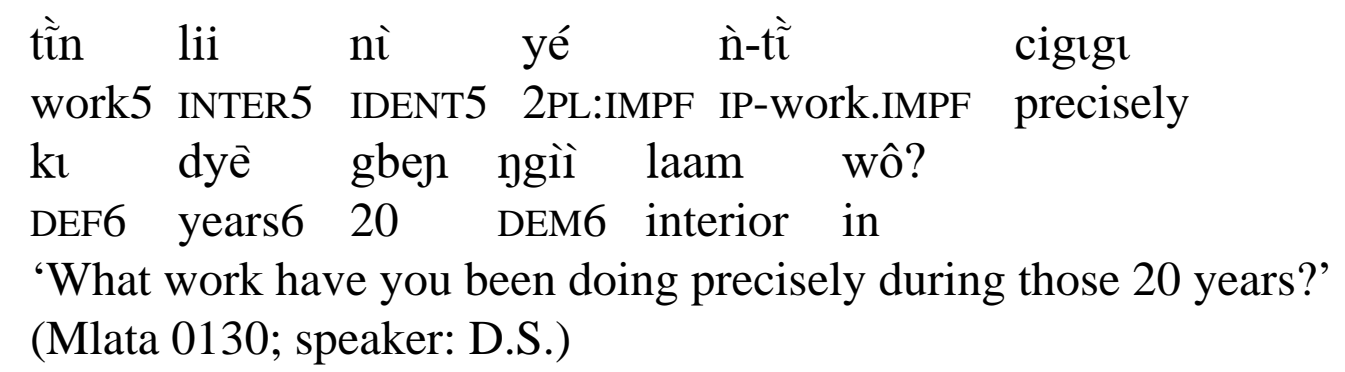

While working on the texts with my main informant, she accepted replacing all the occurrences of a simple pronoun in subject function of the presupposed part of the focus constructions with a background subject pronoun.

The use of simple pronouns instead of background subject pronouns in contexts with an evident argument focus structure seems to be due to the situation in the urban context from which the texts have been taken. In the town of Banfora, Kar speakers live together with speakers of about 40 other languages, using more and more the lingua franca Dyula to communicate with each other. The frequent use of the lingua franca has a detrimental effect on the Kar language, insofar as the second generation only occasionally speaks the parental language and the first generation is losing a number of distinctions in the language. The loss of the distinction between pronouns used especially in presupposed pieces of an utterance and those used in non-presupposed parts is only one point in a series of reductions and simplifications observed in the data. The fact that only our oldest informant uses some other forms of the background 
subject pronouns than those indicated by Wichser in her description (1994) corroborates the hypothesis of the process of loss of an entire function.

\section{$4 \quad$ Coding of focus in different pragmatic conditions}

In the previous sections the different focusing devices existing in Kar have been described. Their coexistence raises the question if it is the communication point that requires the choice of one or the other constructions. It has been mentioned in the introductory notes to the theoretical ideas about focus that some languages subdivide the saliency dimension into several types of saliency on the level of sentence grammar. This is the case of the often cited Aghem. Other languages such as Wambon, a Papuan language do not (de Vries 1985). Neither does Supyire, a Senufo language related to Kar, where the same strategies are used in contrastive focus and in the so called 'strong focus of assertion' (Carlson 1994:468), displayed in replies to constituent questions. Kar seems to behave in a similar way. So cases with clear restrictive focus, using the implicit contrast morpheme ya 'only' occur with all focus strategies: focusing in situ (cf. ex. 21) and fronting with (ex. 10) or without (ex.14) the identification morpheme.

[Context: Differences between former times and the actual period. Roads and vehicles are contrasted with paths and walking.]

yè hĩ̀ ga nàa nnã̃ằr trè̀ ya nî $\mathrm{kl}$ răy 2PL then FUT PROGR IP:walk feet4 only on DEF3 way

'You were then walking (lit. on foot) only.' (Ournan 0986)

On the other hand, completive focus occurs coded in several strategies described, too. Thus, the pragmatic conditions seem neutralized, resulting in the same strategies for completive and for contrastive focus.

Myhill \& Xing (1996) in their outline of an operational definition of contrast discuss the problem of a correspondence between such a function as 'contrast' and one particular construction. They state that there is not necessarily any construction which is only or always used for a function like 'contrast'. This means that a categorical correspondence between one function and one particular construction may not exist. Instead, one is likely to find strong statistical correlations between the function of contrast and the use of a particular construction (Myhill \& Xing 1996:304). However, at the time being, such a statistical analysis of the Kar data is not possible and remains a project for the future.

In conclusion I shall summarise my main findings: I have shown the main focusing strategies of a term in Kar consisting of fronting the focused item and a 
cleft construction. While the combination of the focused item with a focus morpheme is optional in the strategies comprising fronting, it seems to be obligatory for the focusing in situ. In constructions with a fronted focused term, Kar bears some special forms in the presupposed part of the clause, distinguished from those appearing in unmarked clauses. It resembles several other languages in this point. However, while languages such as Wolof (Robert 2000) or Hausa (Creissels 1975) exhibit special verb forms in this part of the construction, Kar shows special subject pronouns, called background subject pronouns. The inconsistency of coding the subject within the presupposed part of clauses containing a focused constituent raised the question if there is some conditioning of the use of background subject pronouns versus simple pronouns. As no morphological, syntactic or pragmatic condition for the use of the one or the other sort of pronoun could be identified, and as the younger speakers have a reduced set of background subject pronouns, I have attributed the inconsistent use to a sociolinguistic situation bringing about simplification and loss in diverse areas of the language.

\section{$5 \quad$ List of abbreviations}

$(<\mathrm{D}) \quad$ borrowing from the lingua BACK background subject pronoun franca Dyula (Mande) DEF definite marking variant from the dialect of DS different subject Boussara

EM variant from the dialect of Labola

1PL first person plural pronoun

1PLBACK first person plural background subject pronoun

FUT emphatic pronoun

IDENT identification morpheme IMPF imperfective INDEF indefinite pronoun INTER interrogative pronoun IP intransitive prefix

1PLREF first person plural reflexive $\mathrm{PF}$ pronoun

PR

2SG second person singular simple pronoun

PROG progressive

REL relative pronoun and

2sGEM second person singular emphatic pronoun

$5 \quad$ class 5 (etc.)




\section{References}

Carlson, Robert J. 1994. A grammar of Supyire. Berlin: Mouton de Gruyter.

Chafe, Wallace L. (1976). Givenness, Contrastiveness, Definiteness, Subjects, Topics, and Point of View. In: Subject and Topic. Li, C.N., ed. pp. 25-55. New York: Academic Press.

Creissels, Denis (1978). Réflexions au sujet de l'article de Maurice Coyaud: 'Emphase, nominalisations relatives' (La Linguistique, vol. 11, fasc. 2/1975). La Linguistique, 14: 117-141.

Dik, Simon C. (1989). The Theory of Functional Grammar. Part I: The Structure of the Clause. Dordrecht: Foris.

Dik, Simon C.; Hoffmann, Maria E.; Jong, Jan R. de; Djiang, Sie I.; Stroomer, Harry; Vries, Lourens de (1981). On the typology of Focus Phenomena. In: Perspectives on Functional Grammar. Hoekstra, T., H.v.d. Hulst, and M. Moortgat, eds. pp. 41-74. Dordrecht: Foris.

Dombrowsky-Hahn, Klaudia (to appear). Kar. In: Noun class systems in Gur languages, Vol. 1. Miehe, G. and K. Winkelmann, eds.

Drubig, H. W.; Schaffar, W. (2001). Focus constructions. In: Language Typology and Language Universals. Haspelmath, M., E. König, W. Oesterreicher, and W. Raible, eds. pp. 1079-1104. Berlin: de Gruyter

Kiss, Katalin É. (1998). Identificational Focus versus Information Focus. Language, 74: 245273.

Lambrecht, Knud (1994). Information structure and sentence form: topic, focus, and the mental representations of discourse referents. Cambridge: Cambridge University Press.

Myhill, John and Zhiqun Xing. (1996). Towards an operational definition of discourse contrast. Studies in Language, 20: 303-360.

Robert, Stéphane (2000). Le verbe wolof ou la grammaticalisation du focus. In: Topicalisation et focalisation dans les langues africaines. Caron, B., ed. pp. 229-267. Paris: Peeters.

Sasse, Hans-Jürgen (1987). The thetic/categorical distinction revisited. Linguistics, 25: 511580.

Thompson, Sandra A.; Longacre, Robert E. (1985). Adverbial clauses. In: Language typology and syntactic description. (Vol.II) Complex constructions. Shopen, T., ed. pp. 171-205. Cambridge: Cambridge University Press.

Vries, Lourens de (1985). Topic and focus in Wambon discourse. In: Syntax and pragmatics in Functional Grammar. Bolkenstein, A.M., C. de Groot, and J.L. Mackenzie, eds. Dordrecht: Foris Publications.

Wichser, Magdalena (1994). Description grammaticale du kar langue senoufo du Burkina Faso (Thèse présentée en vue de l'obtention du Diplôme de l'Ecole pratique des Hautes Etudes). Paris: non-publiée. 
Klaudia Dombrowsky-Hahn 